\title{
UV Spectra of Glycolic Acid Derivatives - A Time-Dependant Density Functional Theory Examination
}

\author{
Mahendiraprabu Ganesan, Selvarengan Paranthaman
}

\begin{abstract}
One of the serious health issues faced by people throughout the world in recent years is Skin cancer, which is caused by harmful $U V$ radiations from the sun. To protect the human skin from direct exposure to these ultraviolet radiations, preventive measures have to be taken and once such solution is the application of suitable and safer sunscreen. It is the need of the hour to develop better and harmless sunscreens to protect the skin. One such material which plays a major role in dermatology and cosmetics industry is Glycolic acid, $\mathrm{CH} 2 \mathrm{OHCOOH,} \mathrm{a} \mathrm{precursor} \mathrm{of}$ a-hydroxy carboxylic acids. Our present study is to find out if the glycolic acid conformers and its derivatives are capable of absorbing harmful radiations in the $U V B$ and $U V A$ ranges. To understand this property the $U V$ absorption spectra is calculated using Time dependant density functional theory (TD-DFT). Further, our TDDFT calculations have shown that o-Nitromandelic acid, a glycolic acid derivative shows absorption in both UVB and UVA regions. This indicates that o-Nitromandelic acid can be probably used as a UV filter in sunscreen lotions.
\end{abstract}

Keywords : UV filter, TD-DFT, Nitromandelic acid, Glycolic acid derivatives.

\section{INTRODUCTION}

$\mathrm{U}_{\mathrm{v}}$ V radiation like UVA, UVB, and UVC radiation [1] are emitted by the sun and are harmful to human skin. We are regularly exposed to the UVB ( 290-320 nm) and UVA $(320-400 \mathrm{~nm})$ radiations [2,3]. In general, the stratospheric region of the ozone layer filters these harmful UVC radiation [4]. But the recent reports of depletion in the ozone layer allows the harmful UV radiation reach the earth's surface. This in turn causes skin damage like erythema (sunburn), cutaneous photoaging, immune suppression, and an increased risk of skin cancer.

Need for organic sunscreens with active UV filters have increased which should not harm the skin as well as protect our skin from damages caused by these harmful radiations. Organic UV filters is one of the most common active constituents in sunscreen products used for attenuating skin photodamage $[1,4,5]$. When the UV radiation falls on the

Revised Manuscript Received on December 09, 2019.

* Correspondence Author

Mahendiraprabu Ganesan, Department of Physics and International Research Centre, Kalasalingam Academy of Research and Education, Krishnankoil-626 126, India. Email: prabuphy24@gmail.com

Selvarengan Paranthaman*, Department of Physics and International Research Centre, Kalasalingam Academy of Research and Education, Krishnankoil-626 126, India. Email: psrengan@hotmail.com organic filters it excites and electron from its ground state to its excited state and this occurs because of the presence of saturated groups ( $\pi$ orbitals) and atoms with unpaired electrons (n orbitals). Some saturated groups that bond to this system also contribute to UV absorption. Similarly, One such material which plays a major role in dermatology and cosmetics industry is Glycolic acid, $\mathrm{CH} 2 \mathrm{OHCOOH}$, a precursor of a-hydroxy carboxylic acids. It also used in the sunscreen products [6-9]. However, very few studies were reported on the related systems both theoretically [10-17] as well as experimentally $[11,12,18,19]$. As far as we have seen from the literatures collected so far, there is no UV spectral study reported in the literature in the glycolic acid conformers and their derivatives. Therefore the purposeof this study is to find out if the glycolic acid conformers and its derivatives have the potential to absorb in the UVB and UVA ranges. Since glycolic acid is used in skin care products, it is necessary to study its UV absorption ranges.

\section{COMPUTATIONAL DETAILS}

The vibrational frequency calculations are performed to identify the minimum energy structure. The time dependent density functional theory (TDDFT) [20,21] calculations with DFT functional, Becke's three parameters exact exchange functional (B3),[22] combined with the Lee-Yang-Parr gradient corrected functional (LYP)[23] with 6-311++G(d,p) basis set is used for the calculations at B3LYP/6-311++G(d,p) level of theory and is performed to understand the UV absorption ranges of the glycolic acid conformers and its derivatives. All the calculations are performed using gaussian09W program.[24]

\section{RESULT AND DISCUSSION}

Since Glycolic acid is an important component of dermatalogical and cosmetic products, it is necessary to study its UV absorption ranges. Hence, in the present study TDDFT calculations at B3LYP/6-311++G(d,p) level of theory are performed on glycolic acid conformers. Our calculations have shown that the GAC conformer of glycolic acid has maximum wavelength $(221.39 \mathrm{~nm})$. From our calculated results, it is understood that the glycolic acid conformers do not show absorption in the UVB/UVA ranges. Hence, we have extended the TDDFT studies on the derivatives of glycolic acid. 
The glycolic acid derivatives chosen in this study are Mandelic acid, $\alpha$-Cyclohexylmandelic acid, p-Bromomandelic acid, Benzilic acid, p-Chloromandelic acid, p.Nitromandelic acid, m-Nitromandelic acid and o-Nitromandelic acid. Totally eight derivatives are taken for this study, to understand their ability to absorb in UVB/UVA ranges. Out of the eight derivatives of glycolic acid, three derivatives namely o-Nitro (alpha-Hydroxy-2-nitrobenzeneacetic acid), p-Nitro (alpha-Hydroxy-4-nitrobenzeneacetic acid) and m-Nitro (alpha-Hydroxy-3-nitrobenzeneacetic acid) mandelic acids show absorption in the UVB and UVA regions and these optimized structures are shown in Fig. 1. The TDDFT calculations have also been performed for the most popular UV filters such as Benzophenone-3 (BZP-3) and Urocanic acid for the comparison purpose.

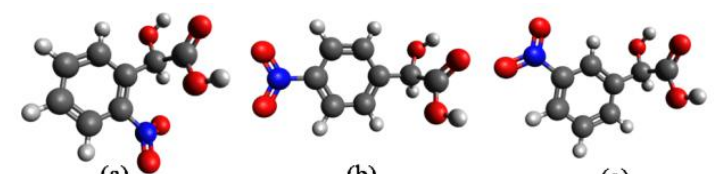

(b)

(c)

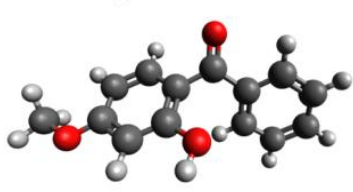

(d)

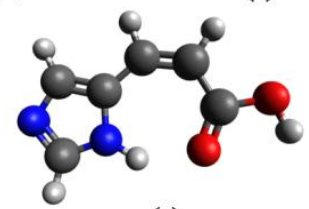

(e)

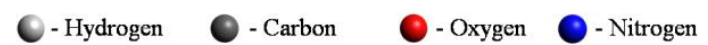

Fig. 1. The optimized structures (a) o-Nitro-, (b)

p-Nitro-, (c) m-Nitromandelic acid of glycolic acid derivatives, (d) BZP-3 and (e) Urocanic acid using B3LYP method.

Figure 2 shows the calculated UV spectrum of glycolic acid derivatives, BZP-3 and Urocanic acid. The UV spectral data can be analyzed using molecular orbital (MO) diagrams. The MO diagrams of the studied glycolic acid derivatives along with BZP-3 and Urocanic acid are shown in Figure 8. The transition energies, wavelengths $(\lambda>280 \mathrm{~nm})$ and the oscillator strengths (f) are obtained from their absorption spectra, and some of the most important transition configurations (HOMO $\rightarrow$ LUMO) are listed in Table 1. From the table, it can be noted that the Nitromandelic acid, a glycolic acid derivative manifest at least one peak in the UVB or UVA range. In the case of o-Nitromandelic acid, the peak observed in the UVB region is owing to the presence of HOMO $\rightarrow$ LUMO transition which is the predominant transition, and its corresponding wavelength is $306 \mathrm{~nm}$ $(\mathrm{f}=0.28)$, for UVA region it is HOMO-1 $\rightarrow$ LUMO transition and the corresponding wavelength is $331 \mathrm{~nm}(\mathrm{f}=0.017)$. In the case of p-Nitromandelic acid, the peak observed in the UVB region is due to HOMO $\rightarrow$ LUMO transition with the wavelength of $287 \mathrm{~nm}(\mathrm{f}=2.44)$ and HOMO-1 $\rightarrow$ LUMO transition with the wavelength of $306 \mathrm{~nm}(\mathrm{f}=0.016)$. In addition to that the $\mathrm{m}$-Nitromandelic acid show absorption in UVB region with the same HOMO $\rightarrow$ LUMO transition, and its corresponding wavelength is $297 \mathrm{~nm}(\mathrm{f}=0.017)$. This indicates that o-Nitromandelic acid show absorption in UVB/UVA regions, whereas other nitromandelic acids show absorption in UVB region only. Therefore, among the three nitromandelic acids, o-Nitromandelic acid could be used as a UV filter. Earlier, Arjunan et. al also studied the experimental and DFT studies on benzohydrazide [12]. They have reported that the vibrational frequency for benzohydrazide was present under UV filter region. They also compared these theoretical data into their experimental results.

Table- I: Calculated Energy (E, eV), wavelength $(\lambda$, nm), oscillator strength (f) and Molecular orbitals

HOMO (H) and LUMO (L) for the glycolic acid derivatives using TD-DFT/B3LYP/6-311++G(d,p) level of theory

\begin{tabular}{lllll}
\hline Derivatives & $\mathbf{E}$ & $\lambda$ & $\mathbf{f}$ & $\begin{array}{l}\text { Molecular } \\
\text { orbitals }\end{array}$ \\
\hline o-Nitromandelic acid & 3.750 & 331 & 0.017 & H-1 $\rightarrow$ L: 0.479 \\
& 4.056 & 306 & 0.028 & H $\rightarrow$ L: 0.647 \\
& 4.264 & 291 & 0.005 & H-2 $\rightarrow$ L: 0.472 \\
\hline m-Nitromandelic acid & 3.775 & 328 & 0.000 & H-2 $\rightarrow$ L: 0.683 \\
& 4.176 & 297 & 0.017 & H $\rightarrow$ L: 0.670 \\
& 4.293 & 289 & 0.001 & H-4 $\rightarrow$ L: 0.615 \\
\hline \multirow{2}{*}{ p-Nitromandelic acid } & 3.242 & 382 & 0.000 & H-2 $\rightarrow$ L: 0.693 \\
& 4.009 & 309 & 0.000 & H-6 $\rightarrow$ L: 0.690 \\
& 4.058 & 306 & 0.016 & H-1 $\rightarrow$ L: 0.507 \\
& 4.325 & 287 & 0.244 & H $\rightarrow$ L: 0.507 \\
\hline Urocanic acid & 3.653 & 339 & 0.014 & H $\rightarrow$ L: 0.415 \\
\hline & 4.078 & 304 & 0.124 & H $\rightarrow$ L: 0.519 \\
\hline & & 305 & 4 & H $\rightarrow$ L: 0.703 \\
\hline
\end{tabular}

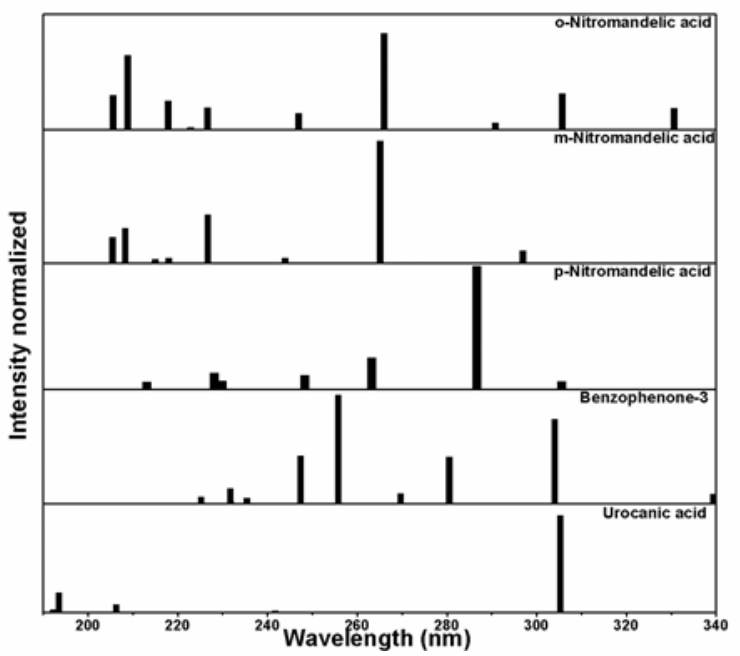

Fig. 2. Comparison of UV spectrum of glycolic acid derivatives with some organic UV filter compounds calculated using TD-DFT/B3LYP/6-311++G(d,p)

Further, our TDDFT studies on BZP-3 have shown that the absorption spectra for UVB and UVA regions are present in the same HOMO $\rightarrow$ LUMO transition with different wavelengths. From Table 1, it can be noted that the UVA wavelength

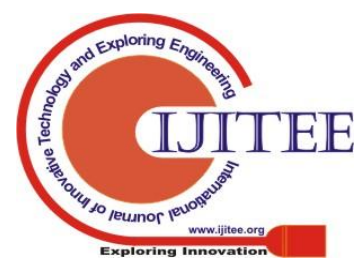


is $339 \mathrm{~nm}(\mathrm{f}=0.014)$ and UVB is $304 \mathrm{~nm}(\mathrm{f}=0.124)$ for BZP-3. The calculated BZP-3 data agrees very well with the experimental data [13]. The UV absorption studies are also performed on cis-Urocanic acid using B3LYP/6-311++G(d,p) level of theory. Our calculations show that the Urocanic acid show absorption in UVB region. In this case, the lowest lying energy transition is HOMO $\rightarrow$ LUMO with the wavelength $305 \mathrm{~nm}(\mathrm{f}=0.48)$. In both BZP-3 and cis-Urocanic acid, HOMO $\rightarrow$ LUMO transition is predominant. From the above discussion, it can be concluded that, o-Nitromandelic acid derivative is one of the best UV filter lying in both UVB and UVA region and is clearly shown in Fig. 3.

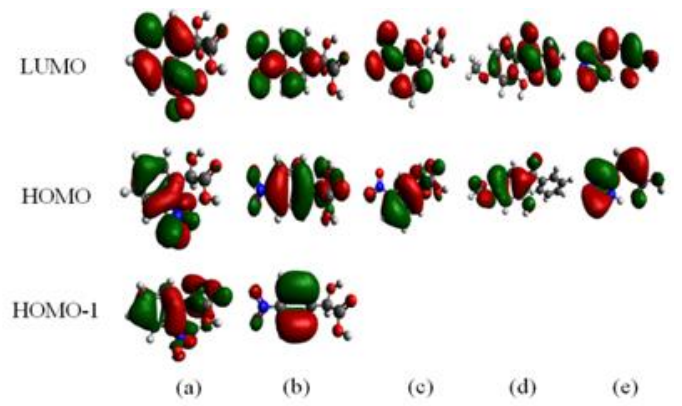

Fig. 3. The molecular orbital diagrams of (a) o-Nitromandelic acid, (b) p-Nitromandelic acid, (c) m-Nitromandelic acid, (d) Benzopenone-3 and (e) Urocanic acid glycolic acid derivatives

The reason is, the molecular orbital transitions for p-Nitro and $\mathrm{m}$-Nitromandelic acids lies between $\alpha$-Hydroxyl group and nitrobenzeneacetic acid group, but in the case of o-Nitromandelic acid, this transition is shifted from nitrobenzene acetic acid group to $\alpha$-Hydroxyl group.

\section{CONCLUSION}

In the present investigation the UV absorption study for the glycolic acid derivatives is calculated using TD-DFT study. From this study, it can be concluded that the o-Nitromandelic acid could be used as UV filter. In addition to this, our theoretical studies, demonstrates the ability of using glycolic acid derivatives as UV filter.

\section{APPENDIX}

It is optional. Appendixes, if needed, appear before the acknowledgment.

\section{ACKNOWLEDGMENT}

M. G. sincerely thanks Kalasalingam Academy of Research and Education for the award of University Research Fellowship (URF). S. P. is thankful to the management of Kalasalingam Academy of Research and Education for providing the financial support to establish the computational research facility at the International Research Centre (IRC), Kalasalingam Academy of Research and Education.

\section{REFERENCES}

1. S. A. Stechschulte, R. S. Kirsner and D. G. Federman, "Sunscreens for non-dermatologists: what you should know when counseling patients," Postgrad. Med., 2011, vol. 123, pp. 160-167.

2. M. V. R. Velasco, T. S. Balogh, C. A. Pedriali, F. D. Sarruf, C. A. S. O. Pinto, T. M. Kaneko and A. R. Baby, "Novas metodologias analíticas para avaliação da eficácia fotoprotetora (in vitro)-revisão," Rev. Cienc. Farm. Basica Apl., 2011, vol. 32, pp. 27-34.

3. S. Q. Wang, Y. Balagula and U. Osterwalder, "Photoprotection: a review of the current and future technologies," Dermatol. Ther., 2010 vol. 23 , pp. 31-47.

4. R.Y. Antony, "Acute effects of UVR on human eyes and skin," Prog. Biophys. Mol. Biol., 2006, vol. 92, pp. 80-85.

5. Y. Gilaberte and S. Gonzalez, "Update on photoprotection," Actas. Dermo-Sifiliogr., 2010, Vol. 101, pp. 659-672.

6. L. S. Moy, H. Murad and R. L. Moy, "Glycolic acid peels for the treatment of wrinkles and photoaging" J. Dermatol. Surg. Oncol., 1993, vol. 19, pp. 243-246.

7. L. S. Moy, K. Howe and R. L. Moy, "Glycolic acid modulation of collagen production in human skin broblast cultures in vitro," Dermatol. Surg., 1996, vol. 22, pp. 439-441.

8. J. C. DiNardo, G. L. Grove, L. S. Moy, "Clinical and histological effects of Glycolic acid at different concentrations and pH levels," Dermatol. Surg. 1996, vol. 22, pp. 421-424.

9. R. G. Males and F. G. Herring, "A 1 H-NMR study of the permeation of glycolic acid through phospholipid membranes," Biochim. Biophys. Acta-Biomembr., 1999, vol. 1416, pp. 333-338.

10. J. Danielsson, J. Ulicny and A. Laaksonen, "A TD-DFT study of the photochemistry of urocanic acid in biologically relevant ionic, rotameric, and protomeric forms," J. Am. Chem. Soc., 2001, vol. 123, pp. 9817-9821.

11. S. J. Shahtaheri, M. Abdollahi, F. Golbabaei, A. Rahimi-Froushani and F. Ghamari, "Optimization of SPE for Analysis of Mandelic Acid as a Biomarker of Exposure to Ethyl Benzene," Iranian J. Env. Health Sci. Eng., 2004, vol. 1, pp. 70-80.

12. V. Arjunan, T. Rani, C. V. Mythili and S. Mohan, "Synthesis, FTIR, FT-Raman, UV-visible, ab initio and DFT studies on benzohydrazide," Spectrochim. Acta Mol. Biomol. Spectrosc., 2011, vol. 79 , pp. $486-496$

13. B. A. Correa, A. S. Goncalves, A. M. de Souza, C. A. Freitas, L. M. Cabral, M. G. Albuquerque, H. C. Castro, E. P. dos Santos and C. R Rodrigues, "Molecular Modeling Studies of the Structural, Electronic, and UV Absorption Properties of Benzophenone Derivatives," J. Phys. Chem. A., 2012, vol. 116, pp. 10927-10933.

14. G. H. Trossini, V. G. Maltarollo, R. D. Garcia, C. A. Pinto, M. V. Velasco, K. M. Honorio and A. R. Baby, "Theoretical study of tautomers and photoisomers of avobenzone by DFT methods," J. Mol. Model., 2015, vol. 21, pp. 319

15. N. Manojai, R. Daengngem, K. Kerdpol, C. Ngaojampa and N Kungwan, "Heteroatom effect on photophysical properties of 2-(2'hydroxyphenyl)benzimidazole and its derivatives as fluorescent dyes: a TD-DFT study," J. Lumin., 2017, vol. 188, pp. 275-282.

16. W. Chansen, R. Salaeh, C. Prommin, K. Kerdpol, R. Daengngern and N. Kungwan, "Theoretical Study on Influence of Geometry Controlling over the Excited-state Intramolecular Proton Transfer of 10-Hydroxybenzo[h]quinoline and Its Derivatives," Comp. Theor. Chem., 2017, vol. 1113, pp. 42-51.

17. T. Mohammad, H. Morrison and H. HogenEsch, "Urocanic Acid Photochemistry and Photobiology," Photochem. Photobiol., 1999, vol. 69, pp. 115-15.

18. J. F. Vimala, M. Lawrence and J. T. J. Prakash, "Growth and characterization of an organic nonlinear optical crystal: Benzilic Acid," Elixir Cryst. Growth., 2011, vol. 42, pp. 5664-5667.

19. S. Tong, H. Zhang, M. Shen, Y. Ito and J. Yan, "Enantioseparation of mandelic acid derivatives by high performance liquid chromatography with substituted $\beta$-cyclodextrin as chiral mobile phase additive and evaluation of inclusion complex formation," J. Chrom. B., 2014, vol 962, pp. 44-51.

20. E. Runge and E. K. U. Gross, "Density-Functional Theory for Time-Dependent Systems," Phys. Rev. Lett., 1984, vol. 52, pp. 997.

21. E. K. U. Gross and W. Kohn, "Time-Dependent Density-Functional Theory," Adv. Quantum Chem., 1990, vol. 21, pp. 255-291.

22. A. D. Becke, "Density-functional exchange-energy approximation with correct asymptotic behaviour," Phys. Rev. A., 1988, vol. 38, pp. 3098-3100 
23. C. Lee, W. Yang and R. G. Parr, "Development of Aolle-Salvetti correlation-energy formula into a functional of the electron density," Phys. Rev. B. 1988, vol. 37, pp. 785-789.

24. M. J. Frisch, G. W. Trucks, H. B. Schlegel, G. E. Scuseria, M. A. Robb J. R. Cheeseman, G. Scalmani, V. Barone, B. Mennucci, G. A Petersson, H. Nakatsuji, M. Caricato, X. Li, H. P. Hratchian, A. F. Izmaylov, J. Bloino, G. Zheng, J. L. Sonnenberg, M. Hada, M. Ehara K. Toyota, R. Fukuda, J. Hasegawa, M. Ishida, T. Nakajima, Y. Honda O. Kitao, H. Nakai, T. Vreven, J. A. Montgomery, Jr., J. E. Peralta, F. Ogliaro, M. Bearpark, J. J. Heyd, E. Brothers, K. N. Kudin, V. N. Staroverov, R. Kobayashi, J. Normand, K. Raghavachari, A. Rendell, J. C. Burant, S. S. Iyengar, J. Tomasi, M. Cossi, N. Rega, J. M. Millam, M. Klene, J. E. Knox, J. B. ross, V. Bakken, C. Adamo, J. Jaramillo, R. Gomperts, R. E. Stratmann, O. Yazyev, A. J. Austin, R. Cammi, C. Pomelli, J. W. Ochterski, R. L. Martin, K. Morokuma, V. G. Zakrzewski, G. A. Voth, P. Salvador, J. J. Dannenberg, S. Dapprich, A D. Daniels, O. Farkas, J. B. Foresman, J. V. Ortiz, J. Cioslowski and D. J. Fox, Gaussian 09, Revision D.01; Gaussian Wallingford, CT, 2009. 